\title{
High efficiency single quantum well graded-index separate-continement heterostructure lasers fabricated with MeV oxygen ion implantation
}

\author{
Fulin Xiong, T. A. Tombrello, H. Wang, a) T. R. Chen, H.Z. Chen, H. Morkoç, and \\ A. Yariv \\ California Institute of Technology, Pasadena, California 91125
}

(Received 26 September 1988; accepted for publication 6 December 1988)

\begin{abstract}
Single quantum well AlGaAs/GaAs graded-index separate-confinement heterostructure lasers have been fabricated using $\mathrm{MeV}$ oxygen ion implantation plus optimized subsequent thermal annealing. A high differential quantum efficiency of $85 \%$ has been obtained in a $360-\mu \mathrm{m}$-long and 10- $\mu$ m-wide stripe geometry device. The results have also demonstrated that excellent electrical isolation (breakdown voltage of over $30 \mathrm{~V}$ ) and low threshold currents ( $22 \mathrm{~mA}$ ) can be obtained with MeV oxygen ion isolation. It is suggested that oxygen ion implantation induced selective carrier compensation and compositional disordering in the quantum well region as well as radiation-induced lattice disordering in $\mathrm{Al}_{x} \mathrm{Ga}_{1-x} \mathrm{As} / \mathrm{GaAs}$ may be mostly responsible for the buried layer modification in this fabrication process.
\end{abstract}

Pabrication of high quantum efficiency and low threshold semiconductor lasers has attracted considerable attention in recent years. ${ }^{1-3}$ One limit to device performance is the leakage current (current which bypasses the active region of the device). In addition to several conventional methods such as diffusion, etching, and burying insulation layer growth, all of which have been shown to have some technical difficulties, ion implantation may provide some advantages. It has been established that selected ion species may create insulating or semi-insulating layers in semiconductor crystals. Such high-resistivity layers placed in appropriate regions can block current fow through undesired leakage paths in semiconductor lasers. In the AlGaAs-GaAs material system, proton implantation, which utilizes the lattice damage mechanism, was first used to demonstrate this possibility. ${ }^{4.5}$ Oxygen ion implantation by chemical doping has been shown to result in a stable semi-insulating material ${ }^{6,7}$ and has previously been reported as a current confinement technique for planar stripe lasers. ${ }^{8,9}$ This is also a potentially promising technique for current confinement in AlGaAs/ GaAs chaneled substrate planar lasers. ${ }^{10}$ Some work on Be or Fe ion implantation into the InGaAsP/hP system for laser fabrication has also been reported. ${ }^{1,12}$ However, most of the above-mentioned investigations were carried out by preparing a semi-insulating layered substrate through ion implantation followed by liquid phase expitaxial (LPE) growth of active and cladding layers on top. We rep̧ort in this letter the utilization of $\mathrm{MeV}$ oxygen ion implantation for direct fabrication of single quantum well (SQW) gradedindex separate-confinement heterostructure (GRINSCH) AlGaAs/GaAs lasers. We have taken advantage of selective carrier compensation, chemical doping, and implantationinduced compositional disordering with Al interdifusion to improve the device performance with respect to efficiency and threshold current, and obtain improved electrical characteristics.

\footnotetext{
a) Present address: Centre National d'Etudes des Télécommunication, Laboratory of Bagneux, 196 avenue Heni Ravera, F-92220, Bagneux, France.

b) Permanent address: The Coordinated Science Laboratory, University of Ilinois at Urbana-Champaign, Urbana, IL 61801.
}

Figure 1 shows a sketch of the SQW-GRINSCH AlGaAs/GaAs layer structure. It was grown by the molecular beam expitaxy (MBE) method on an $n$-type Si-doped $\langle 100\rangle$ oriented GaAs substrate. A $2 \mu \mathrm{m}$ GaAs buffer layer with uniform composition was first grown on the substrate in order to reduce substrate-related defects. Following the growth of a Si-doped $\mathrm{Al}_{0.5} \mathrm{Ga}_{0.5}$ As cladding layer, a $70 \AA$ quantum well active layer was sandwiched between two graded-index AlGaAs waveguide layers of $1500 \AA$ thickness, in which the Al mole fraction was varied from $x=0.5$ to $x=0.2$ towards the quantum well. These graded-index AlGaAs layers provide parabolic waveguide regions for vertical confinement both for electrical carriers and the optical field. The growth was then continued with a Be-doped $\mathrm{Al}_{0.5} \mathrm{Ga}_{0.5}$ As upper cladding layer and a $\mathrm{GaAs}$ cap contact layer.

For lateral confinement, $\mathrm{MeV}$ oxygen ion implantation was employed, as indicated schematically in Fig. 2. The processing of the device began with delineating the mask stripes along the $\langle 110\rangle$ direction on the surface by using photolithography. The mask stripe is $10 \mu \mathrm{m}$ wide and consists of a 3500 A gold film with a 4-um-thick photoresist (AZ4400) layer on top. It defines the laser cavity width and provides

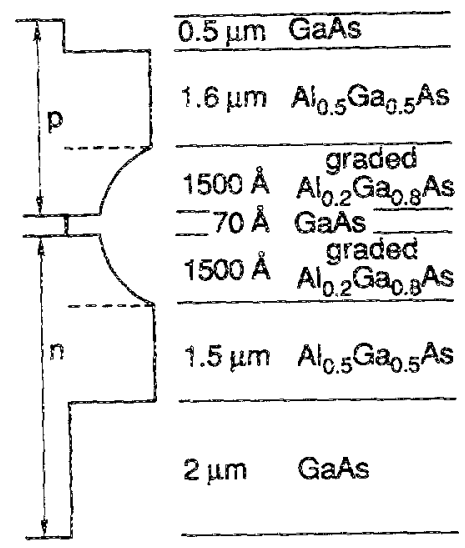

FIG. 1. Sketch of the layer structure of a single quantum well GRINSCH AlGaAs-GaAs laser grown by the MBE method. 


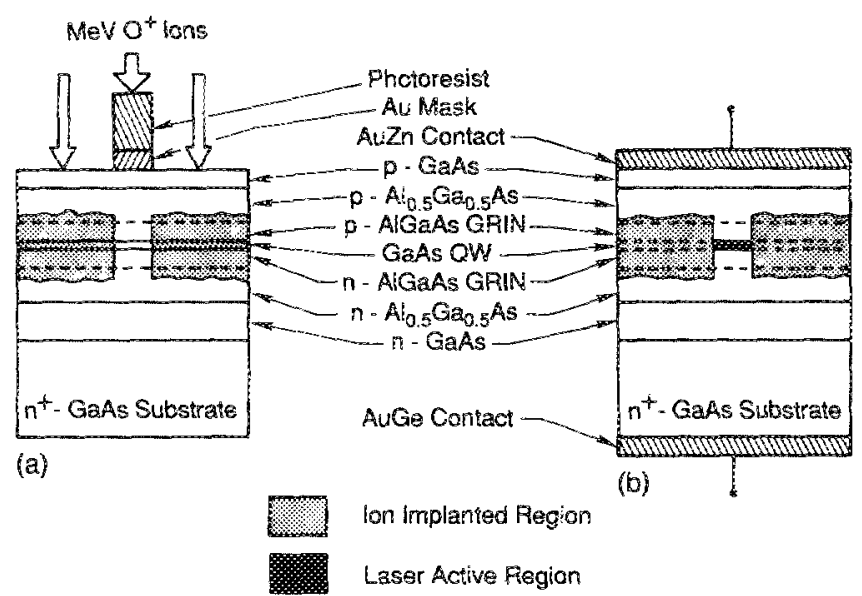

FIC. 2. Cross-sectional views of (a) a masked and as-implanted single quantum well GRINSCHL lascr device chip and (b) an oxygen ion implantation fabricated laser device with such a structure.

encugh material to prevent the $2 \mathrm{MeV}$ oxygen ions from reaching the lasing region and causing implantation damage. Ion implantation was carried out at room temperature using the Caltech Tandem accelerator. The beam energy of $1.8 \mathrm{MeV}$ was chosen according to our data on oxygen ion range versus beam energy in GaAs and photoresist as well as standard stopping power data. The best results were obtained when the implanted layer straddled the graded-index regions and the quantum well layer in the device. A dose of $2 \times 10^{15} / \mathrm{cm}^{2}$ was found to be optimal with a beam flux under $1 \mu \mathrm{A} / \mathrm{cm}^{2}$. A diagram of the masked and as-implanted sample is shown in Fig. 2(a).

Following implantation the mask was removed by etching the sample in $\mathrm{HCl}$ acid for 1 min for the photoresist layer, followed by etching in a commercial gold etchant for the Au film. The sample was then annealed in a graphite heater at $650^{\circ} \mathrm{C}$ for $10 \mathrm{~min}$ in $\mathrm{N}_{2}$ ambient gas. This optimim condition was determined in a test of the annealing procedure for oxygen-implanted $n$-type and p-type GaAs, where we observed the effect of selective carrier compensation as we will discuss below. Finally, the AuZn was deposited to contact the surface $p$-type GaAs, and AuGe was evaporated on the backside to contact the n-type GaAs substrate. These metal contacts were alloyed at $450^{\circ} \mathrm{C}$ for $20 \mathrm{~s}$. The individual laser chips were then cleaved without subsequent coating for testing. A schematic diagram of a fabricated device is shown in Fig. 2(b).

For comparison, a $\mathrm{SiO}_{2}$ stripe geometry laser was also fabricated from the same MBE-grown wafer as that used for implantation fabricated devices. The $\mathrm{SiO}_{2}$ layer was $2000 \AA$ thick and was thermally grown on the sample surface. The laser stripe was $10 \mu \mathrm{m}$ wide and the cavity was $420 \mu \mathrm{m}$ long.

Optical characterization of the fabricated lasers was performed at room temperature under a probe station. For a typical device of cavity length $360 \mu \mathrm{m}$, the lasing emission wavelength is $0.842 \mu \mathrm{m}$. The output power per facet versus the pulsed injection current is shown in Fig. 3. One finds that the threshold current is about $22 \mathrm{~mA}$. A total siope efficiency (both as-cleaved facets combined) associated with this particular laser is about $1.25 \mathrm{~W} / \mathrm{A}$. A total external quantum efficiency over $85 \%$ was obtained. As a comparison, the output characteristic curve of a $\mathrm{SiO}_{2}$ stripe laser has also been

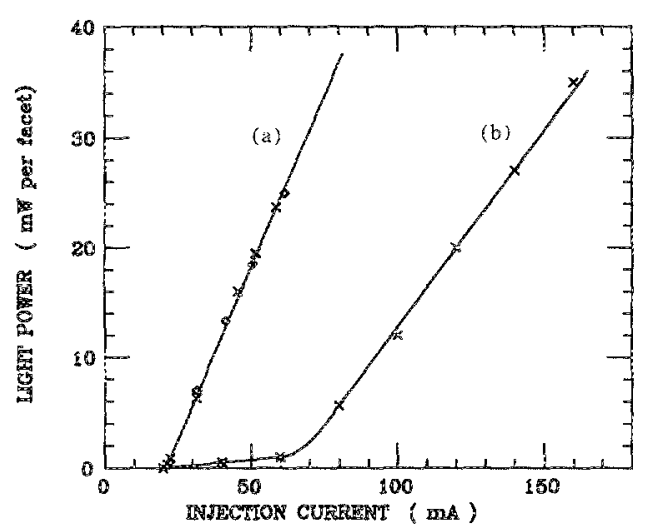

FIG. 3. Eight-output characteristics of a single quantum well GRINSCH AlGaAs-GaAs laser fabricated (a) by high-energy oxygen ion implantation with a cavity of $10 \mu \mathrm{m} \times 360 \mu \mathrm{m}\left(I_{\mathrm{th}}=22 \mathrm{~mA}, \gamma_{\mathrm{exp}}=85 \%\right)$ and (b) with $\mathrm{SiO}_{2}$ isolating stripe with a cavity of $10 \mu \mathrm{mb} \times 420 \mu \mathrm{m}\left(I_{\mathrm{H}}=65 \mathrm{~mA}\right.$, $\eta_{\text {exp }}=5(\%)$.

plotted in Fig. 3, where it is shown that the threshold current in this $10-\mu \mathrm{m}$-wide and $420 \mu \mathrm{m}$ stripe laser is about $65 \mathrm{~mA}$ and the total external quantum efficiency is about $51 \%$.

The electrical characteristics of the implanted laser diode were also measured. A typical current-voltage curve is presented in Fig. 4. A low leakage current and a high and sharp reverse breakdown voltage of over $30 \mathrm{~V}$ have been obtained.

Oxygen ion implantation as a means of creating semiinsulating layers in GaAs was first reported by Favennec et $a l .^{6}$ Recently, it has aiso been reported that a similar result can be achieved in AlGaAs. ${ }^{13}$ In contrast to proton bombardment, where the insulating effect is mainly due to lattice damage, oxygen ion implanted $n$-type GaAs and AlGaAs remain insulating after annealing above $600^{\circ} \mathrm{C}$. As damage due to bombardment normally disappears at this temperature, the insulating properties are ascribed to chemical doping with oxygen in the restored lattice. ${ }^{7}$ However, a different effect has been found in $p$-type GaAs material. It exhibits a feature similar to the proton implanted samples. ${ }^{14}$ It is believed that the eiectrical isolation in oxygen ion implanted GaAs is due to oxygen associated deep levels in $\mathrm{GaAs}$, which trap electrons but not koles. ${ }^{714}$ Our experiments in testing samples have further confirmed this phenomenon. If $n^{+}$. and $p^{+}$-iype GaAs samples are implanted with $1 \mathrm{MeV}$ oxygen ions and annealed at temperatures under $600^{\circ} \mathrm{C}$, both samples were insulating, which was mainly due to residual

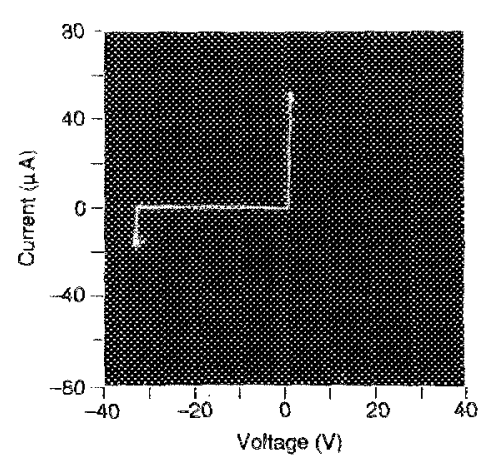

FIG. 4. Electrical characteristics of a single quantum well GRINSCH AIGaAs-GaAs laser fabricated by high-energy oxygen ion impiantation as shown in Figs. 2 and 3. 


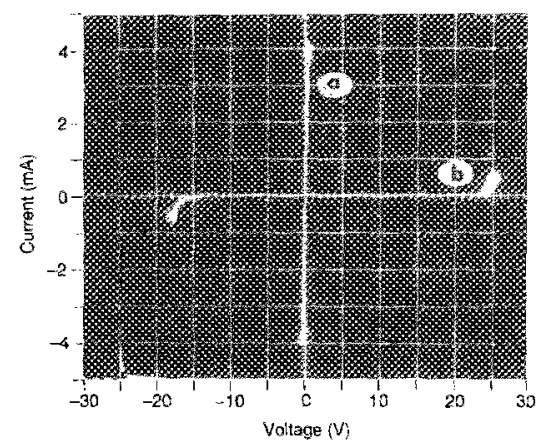

FIG. 5. Current-voltage characteristic curves of oxygen ion implanted and annealed $\left(650^{\circ} \mathrm{C}\right) \mathrm{GaAs}$ single crystals: (a) p-type GaAs, conducting; (b) n-type GaAs, insulating.

raciation damage. The resuit is different after they are annealed above $600^{\circ} \mathrm{C}$. Figure 5 presents the current-voltage characteristic curve which was taken from GaAs samples annealed at $650^{\circ} \mathrm{C}$. It illustrates the conducting behavior in the $p$-type material (curve a) and the insulating behavior in the $n$-type material (curve b). With this selective electrical compensation in GaAs, the requirements on the mask buildup and beam energy selections are more flexible. Since the isolation in oxygen ion implanted GaAs and AlGaAs is not due to radiation damage, which can be annealed at temperatures above $600{ }^{\circ} \mathrm{C}$, the implanted layer can recover its high quality crystalline structure. Thus, optical absorption is greatly reduced in the ion implanted isolation layers compared to proton implanted layers. This results in low threshold current and enhanced quantum efficicncy in oxygen ion implanted lasers.

Compositional disordering in an AlGaAs/GaAs quantum well induced by ion implantation is another accompanying effect, of which one can take advantage in the laser fabrication. If the GaAs quantum well is intermixed with surrounded $\mathrm{Al}_{x} \mathrm{Ga}_{1} \ldots$. $\mathrm{As}$ barriers outside the stripe area, then there is an increase in AlAs mole fraction in the waveguide region outside stripe, efiectively decreasing the refractive index and thus laterally confining the light as well as the carriers. In fact, quantum well layer disorcering, and the resulting shift from low gap to high gap, has been employed to fabricate sophisticated buried heterostructure lasers, ${ }^{1.5-17}$ where the layer disordering was induced by impurity diffusion followed by thermal annealing. Ton implantation can provide more cfective, selective, and maskable means to induce compositional disordering. ${ }^{18}$ The experiments indicate that implantation damage alone is sufficient for quantum well heterostrueture or superiattice layer disordering, but an active impurity ensures more complete disordering. This effect has been observed in $\mathrm{Si}, \mathrm{Zn}, \mathrm{Al}, \mathrm{Ar}$, and $\mathrm{Kr}$ ion implanted superlattices. ${ }^{19-21}$ Recently, our preliminary work ${ }^{22}$ by secondary-ion mass spectrometry profiling and cross-sectional transmission electron microscopy imaging has revealed that lattice compositional disordering in oxygen ion implanted AlAs/GaAs is also realized with Al interdiffusion around the implanied region. The result provides evidence of the disordering in AlGaAs/GaAs quantum well devices.
In summary, single quantum well GRINSCH lasers have been fabricated using high-energy oxygen ion implantation in combination with optimized thermal annealing. High external quantum efficiency, low threshold current, and excellent electrical characteristics were obtained. This technique requires fewer critical processing steps than those previously employed. It is shown that oxygen ion induced selective electrical compensation in $n$-type GaAs and AlGaAs as well as implantation-induced lattice disordering around the quantum well layer provides good electrical isolation for lateral current confinement. Oxygen ion bombardment can also induce Al composition interdiffusion in AlGaAs/GaAs superlattices, giving the desired effect of compositional disordering in the quantum well layer and graded-index regions, thus providing lateral optical confinement and reduced optical loss. A detaled investigation of this effect is under way.

The authors wish to express their gratitude to M. Mittistein for his assistance in the measurements. This work was supported in part by the National Science Foundation (DMR86-15641) and the Office of Naval Research (contract N00014-85-K-0032).

'J. R. Shealy, Appl. Phys. Lett. 52, 1455 (1988).

${ }^{2}$ K. Y. Lau, B. L. Derry, and A. Yariv, Appl. Phys. Lett. 52, 88 (1988).

${ }^{3}$ I. I. Derry, A. Yariv, K. Y. Lau, N. Bar-Chaim, K. Lee, and J. Rosenberg, Appl. Phys. Lett. 50, 1773 (1987).

'J. C. Dyment, J. C. North, and L. A. D'Asaro, J. Appl. Phys. 44, 207 (1973).

${ }^{5}$ J. C. Dyment, I. A D'Asaro, J. C. North, B. I. Miller, and J. E. Ripper, Proc. IEEE 60, 726 (1972).

"P. N. Favennec, G. P. Pelous, M. Binet, and P. Baudet, in Ion Implantation in Semiconductors and Other Materials, edited by B. L. Crowder (Plenum, New York, 1973), p. 621.

7p. N. Farennec, J. Appl. Phys. 47, 2532 (1976).

J. M. Bhum, J. C. McGroddy, P. G. McMulhn, K. K. Shih, A. W. Smith, and I. F. Ziegler, IEEE J. Quantum Electron. QE-11, 413 (1975).

"H. Beneking, N. Grote, H. Krathe, and W. Roth, IFEE J. Quanium Electron. QR-16, $500(1980)$.

${ }^{10}$ N. Grote, H. Kraulte, and $\mathrm{H}$. Beneking, in Gollium Arsenide and Related Compounds, Inst. Phys. Conf. Ser. 45, 484 (1979).

"S. Uchiyama, K. Moriki, K. Iga, and S. Furukawa, Jpn. J. Appl. Phys. Left. 21, L639 (1982).

${ }^{12}$ D. P. Wilt, B. Schwartz, B. Tell, E. D. Beebe, and R. T. Nelson, Appl. Phys. Lett. 44, 290 (1984).

${ }^{13} \mathrm{~S}$. I. Pearton, M. P. Fannuzzi, C. L. Reynolds, $J_{r}$, and L. Peticolas, Appl. Phys. Lett. 52, 395 (1988).

"H. Beneking, N. Grote, and H. Krautle, Solid-State Electron. $2 \mathcal{2}, 1039$ (1979).

${ }^{15}$ T. Fukezaida, S. Semura, H. Saito, T. Ohta, Y. Uchida, and H. Makashima, Appl. Phys. Lett. 45, 1 (1984).

"K. Meehan, P. Gavrilovic, N. Holonyak, Jr., R. D. Burnkam, and R. L. Thornton, Appi. Phys. Lett. 46, 75 (1985).

79. Gavrilovic, K. Meehan, I. E. Epler, N. Holonyak, Ir., R. D. Burnhan, R. L. Thornton, and W. Streifer, Appl. Phys. Lett. 46, 857 (1985).

${ }^{16}$ Y. Firayama, Y. Suzuki, and H. Okanoto, Jpn. J. Appl. Phys. 11, 1498 (1985).

${ }^{19}$ P. Gavrilovic, D. G. Deppe, K. Meehan, N. Holonyak, Jr., J. I. Coleman, and R. D. Burnham, Appl. Phys. Lett. 47, 130 (1985).

${ }^{20} \mathrm{~T}$. Venkatesan, S. A. Schwarz, D. M. Hwang, R. Bhat, M. Koza, H. W. Yoon, B. Mei, Y. Arakawa, and A. Yariv, Appl. Phys. Lett. 49, 701 (1986).

${ }^{2}$ S. A. Schwarz, T. Venkatesan, R. Bhat, M. Koza, H. W. Yoon, Y. Arkawa, and P. Mei, Mater. Kes. Soc. Symp. Proc. 56, 321 (1986).

${ }^{22} \mathrm{~S}$. A. Schwarz (private communication, unpublished). 